\title{
A special technique for determining the bond strength of micro-fibres in cement matrix by pullout test
}

A. KATZ*, V. C. LI

Advanced Civil Engineering Materials Research Laboratory, Department of Civil \& Environmental Engineering, University of Michigan, Ann Arbor, MI 48109-2125, USA

The complete relationship between the pullout load and the displacement of a fibre when it pulls out of the matrix serves as an important parameter in the design of composite materials. Many analytical models for the prediction of the behaviour of composite materials are based on the assumption of a constant friction load between the fibre and the matrix, regardless of the displacement of the fibre. Based on this assumption test techniques were developed $[1,2]$ in which the critical length of the fibre was determined. The bond strength was calculated from the critical length assuming that the fibre strength and diameter are known. The two techniques are quite similar, and were found by [1] as inapplicable for extremely brittle fibres such as carbon fibres.

In addition, some pullout tests suggest an interface friction which depends on the amount of local slippage [3]. Such slip-dependency cannot be identified by test methods based on measuring the critical fibre length only.

In the following a detailed description of the new technique used for the determination of the complete $\mathrm{P}-\mathrm{u}$ (pullout load-fibre displacement) curve of micro-fibres from cement matrix will be described. There is an increasing trend in recent years towards the use of micro-fibres in cement reinforcement. Micro-fibres can be defined as those with diameter equal to or smaller than cement grain size, typically in the range $10-20 \mu \mathrm{m}$.

Problems which arise when making a direct pullout test of carbon fibre from cementitious matrix include:

(1) The carbon fibre is very fine $(6-15 \mu \mathrm{m})$ and extremely brittle.

(2) Deflection of the fibre in the matrix while casting or vibrating leads to an increase in the apparent pullout load (a deflection of $10^{\circ}$ from the desired origin may lead to an increase of up to $20 \%$ in the pullout load [4]).

(3) The matrix is very thick relative to the fine fibre, thus the fibre is pushed by the matrix while casting and fibre deflection or breakage may occur.

(4) Direct handling of the fibres must be minimized at all stages of the specimen preparation process.

\footnotetext{
*Present address: National Building Research Institute, Department of Civil Engineering, Technion-Israel Institute of Technology, Haifa 32000, Israel
}

(5) The homogeneity of the matrix around the fibre must be ensured.

Casting setup. The setup of the fibres and mould and a cross-section through it are presented in Figs 1 and 2e. Dimensions are not marked and must be determined for each individual needs. All mould materials were made of Plexiglas.

The side units, $U_{b}$ and $U_{t}$ must be made very accurately, having a thickness of half of the total specimen thickness. The edges need to be rightangled without a curvature to minimize matrix bleeding in between the units. Units $U_{t}$ are connected right on top of units $U_{b}$ ensuring a straight finish to the edge of the specimen. The other two units $U_{\mathrm{s}}$ have no important role except for preventing the matrix from spilling to the sides.

The frame is used to position the fibres precisely without movement during casting and vibrating. Two double-sided adhesive tapes are used to attach the fibres to the frame.

Casting is done in the order shown in Fig. $2 \mathrm{a}$ to $2 \mathrm{e}$ with the following emphasis. Environmental electron scanning microscope (ESEM) observations showed

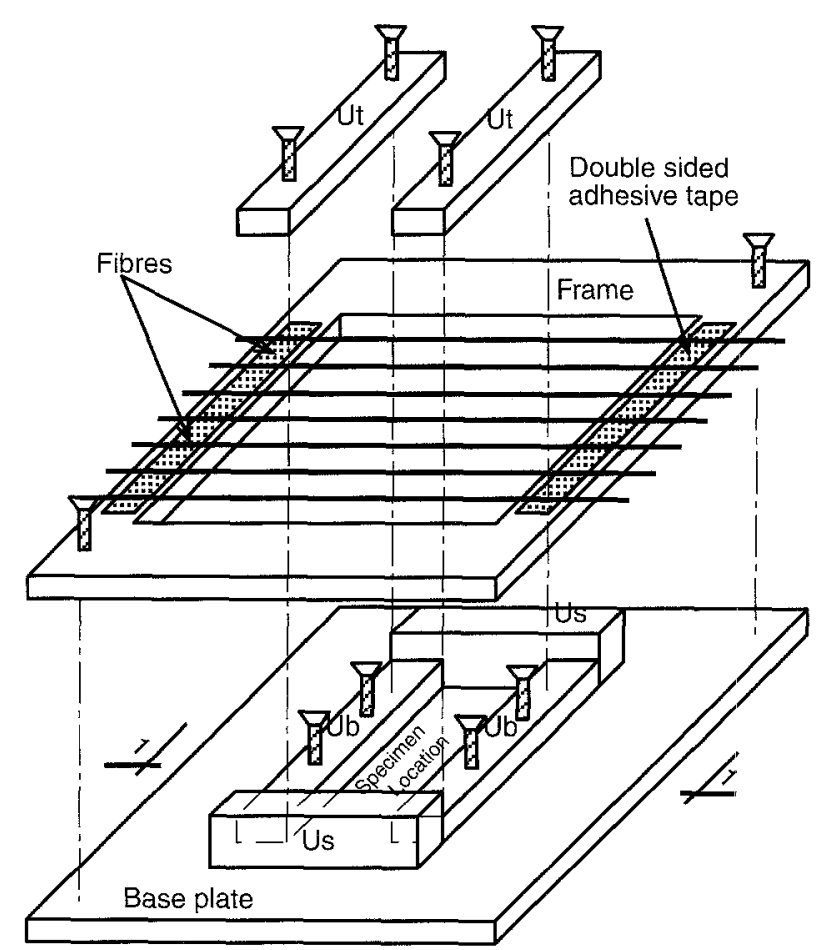

Figure I Setup of the mould and the fibres. 


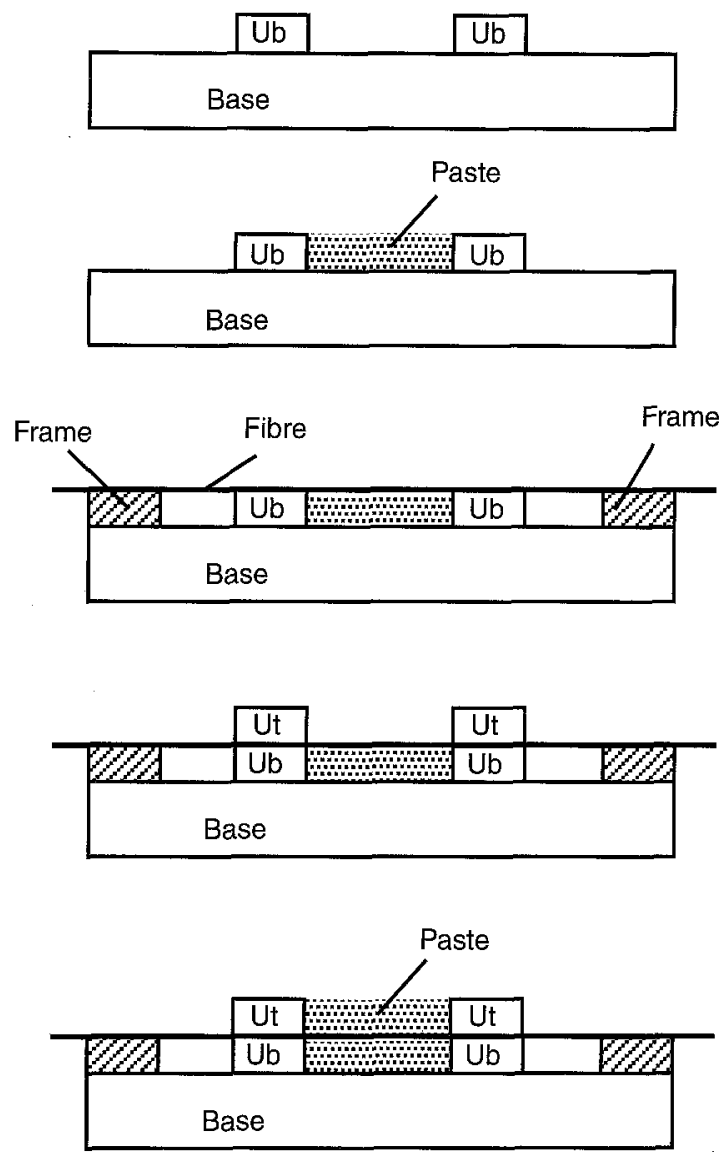

(a)

(b)

(c)

Figure 2 Cross-section 1-1 through the mould and working order.

that vibration alone when casting the second layer of paste (see Fig. 2e) is not sufficient for good mixing of the two layers of paste. Although the whole process lasts less than $5 \mathrm{~min}$, a narrow crack of $1-$ $4 \mu \mathrm{m}$ was seen between the two layers of paste along the specimen when vibration alone was used. Thus, additional mixing between the fibres with the help of a needle is needed to ensure good mixing.

Demoulding is done simply by cutting the fibres close to the frame, and removing carefully the units $\mathrm{U}_{\mathrm{t}}, \mathrm{U}_{\mathrm{b}}$ and $\mathrm{U}_{\mathrm{s}}$.

Preparation for testing. Small specimens containing 1-3 fibres (Fig. 3b) are sawn out of the specimen (Fig. 3a). The cutting is done along the dashed line in Fig. 3a using a precise diamond saw. The thickness of the small specimen, $L$, can be determined as needed. Usually the longest embedment length, $L_{\mathrm{c}}$, still enabling complete pullout of the fibre without rupture, is preferred. This length can be determined from Equation 1 using the estimated fibre-matrix bond, $\tau_{\text {est }}$.

$$
L_{\mathrm{c}}=\frac{\sigma_{\mathrm{f}} d}{4 \tau_{\mathrm{est}}}
$$

where $\sigma_{\mathrm{f}}$ is fibre tensile strength and $d$ is fibre diameter.

Typical $\mathrm{L}_{\mathrm{c}}$ values for high-strength carbon fibre $\left(\sigma_{\mathrm{f}}=2900 \mathrm{MPa}\right.$ and $\left.d=7 \mu \mathrm{m}\right)$ are $3-10 \mathrm{~mm}$ for bond strengths of 0.5 to $1.5 \mathrm{MPa}$, respectively.

Testing. A sensitive load cell having a low capacity corresponding to the loads needed in the test must be used. The base of the specimen is glued

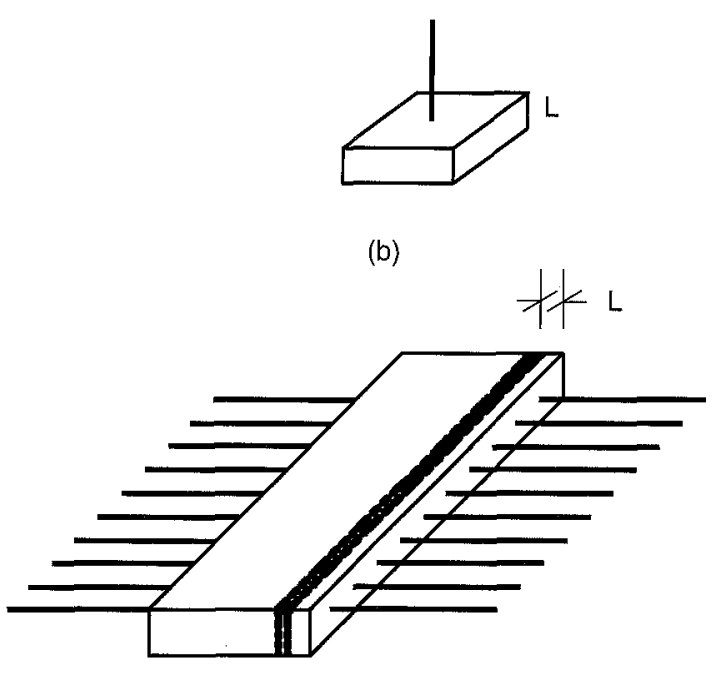

(a)

Figure 3 Specimen after demoulding (a) and cutting (b).

onto the load-cell stage after the latter has already been installed on the testing machine. This step results in a carbon fibre hanging downwards from the specimen base. After hardening of the adhesive, the free edge of the fibre is glued to the testing machine with a fast hardening glue. This method of attaching the specimen to the testing machine in situ ensures accurate alignment of the fibre and prevents bending of the fibre while testing, or a sudden break of the fibre while setting the machine.

Test results. Test results of the pullout of fine polymeric fibre (Spectra 900) having a diameter of $42 \mu \mathrm{m}$ pulled from a cement matrix (Fig. 4) were compared with known results from the literature [5] (Fig. 5), where a conventional test setup with a halfdog-boned-shape specimen was used. The results showed good similarity between the two methods, both in the value of peak load (relative to the embedded length) and in the shape of the complete $\mathrm{P}-\mathrm{u}$ curve. In both cases, a slip-hardening pullout curve was observed. The slip-hardening behaviour was associated with fibre surface abrasion [4].

Figs 6 and 7 present pullout results of thin and thick carbon fibres from a cement matrix, respectively. The bond mechanism of these fibres to the cement matrix seems to be different from that of the

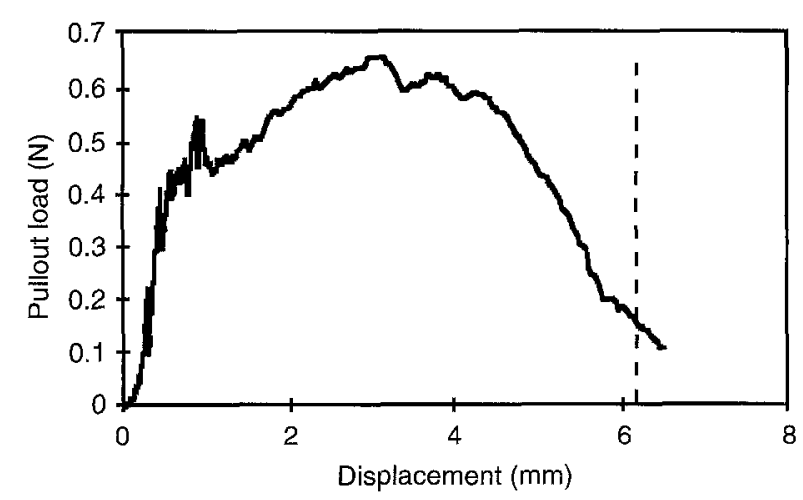

Figure 4 Load-displacement curve of polymeric fibres using the present technique: $d=42 \mu \mathrm{m} ; L=6.2 \mathrm{~mm}$. 


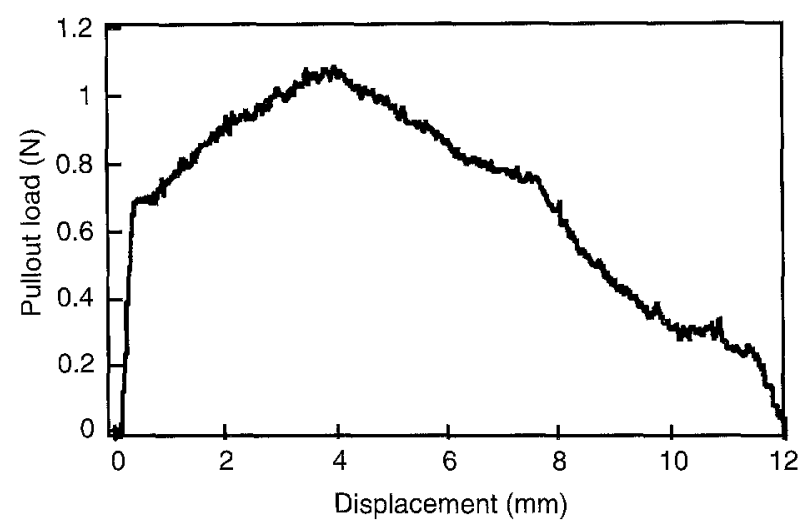

Figure 5 Load-displacement curve of polymeric fibres pulled in a conventional method: $\mathrm{d}=38 \mu \mathrm{m} ; L=12 \mathrm{~mm}$.

polymeric fibre. For the thin fibre $\left(\sigma_{\mathrm{f}}=1970 \mathrm{MPa}\right.$ and $d=10 \mu \mathrm{m}$ ), the bond mechanişm seems to be of pure friction leading to linear decrease of the pullout load as the fibre is pulled out of the matrix (Fig. 6). A mechanism of slip softening (Fig. 7) seems to be the main mechanism developed as the bond increases for thick carbon fibres $\left(\sigma_{\mathrm{f}}=930 \mathrm{MPa}\right.$ and $d=46 \mu \mathrm{m})$. It is possible that penetration of hydration products into long narrow grooves along the surface of the fibre, which were observed by ESEM [6], yielded good anchoring of the fibre in the matrix. Breakage of this anchor while the fibre pulls out yields rapid decrease of the pullout load, which appears as slip-softening. Details of the influence of silica fume and $\mathrm{w} / \mathrm{c}$ ratio on interfacial bond strength of carbon fibre can be found in [6].

Conclusions. The development of a novel method

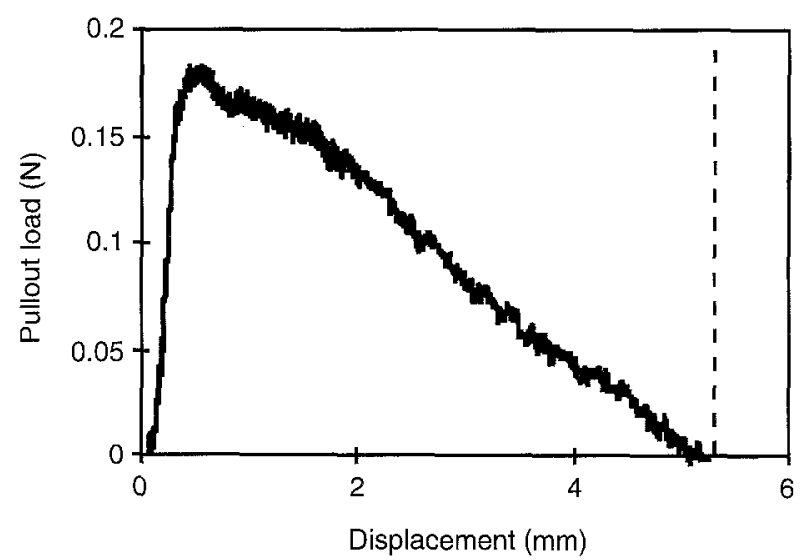

Figure 6 Load-displacement curve of thin $(10 \mu \mathrm{m})$ carbon fibre: $\mathrm{L}=5.3 \mathrm{~mm}$.

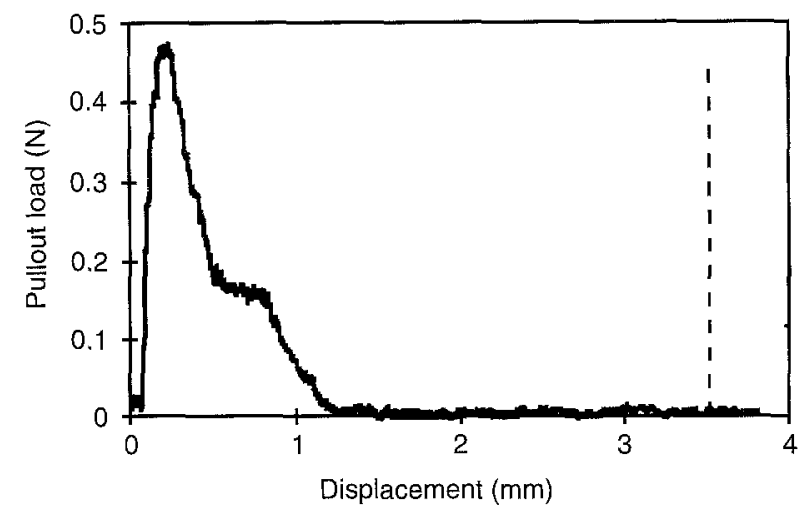

Figure 7 Load-displacement curve of thick (46 $\mu \mathrm{m}$ ) carbon fibre: $\mathrm{L}=3.5 \mathrm{~mm}$.

for direct pullout of micro-fibres from a cement matrix enables the testing of micro-fibres having an extremely brittle nature which could not previously be tested. Using this method, the pullout mechanism of carbon fibre from a cement matrix was studied successfully, providing details which could not be obtained previously by other known techniques.

\section{Acknowledgements}

This research was partially funded by a grant from Conoco, Inc. to the ACE-MRL at the University of Michigan and a grant from the National Science Foundation (NSF MSS-9301949). Special thanks are due to Drs J. McConaghy and A. J. Kazmer for many helpful discussions.

\section{References}

1. Y. WANG, S. BAKER and V. C. LI, J. Mater. Sci. Lett. 7 (1988) 842.

2. B. K. LARSON, L. T. DRZAL and P. SOROUSHIAN, Composites 21 (1990) 205

3. Y. WANG, V. C. LI and S. BACKER, in Materials Research Society Symposia Volume 114: Bonding in Cementitious Composites, edited by S. Mindess and S. Shah, (1988) p. 159

4. V. C. LI, Y. WANG and S. BACKER, J. Compos. 21 (1990) $132-140$.

5. V. C. LI, H. C. WU and Y. W. CHAN, J. Amer: Ceramics Soc. 79 (1996) 700 .

6. A. KATZ, V. C. LI and A. KAZMER, ASCE J. Mater: Civil Engng 7 (1995) 125.

Received 30 November 1995

and accepted 8 July 1996 